

\section{DISCLAIMER}

This report was prepared as an account of work sponsored by an agency of the United States Government. Neither the United States Government nor any agency Thereof, nor any of their employees, makes any warranty, express or implied, or assumes any legal liability or responsibility for the accuracy, completeness, or usefulness of any information, apparatus, product, or process disclosed, or represents that its use would not infringe privately owned rights. Reference herein to any specific commercial product, process, or service by trade name, trademark, manufacturer, or otherwise does not necessarily constitute or imply its endorsement, recommendation, or favoring by the United States Government or any agency thereof. The views and opinions of authors expressed herein do not necessarily state or reflect those of the United States Government or any agency thereof. 


\section{DISCLAIMER}

Portions of this document may be illegible in electronic image products. Images are produced from the best available original document. 


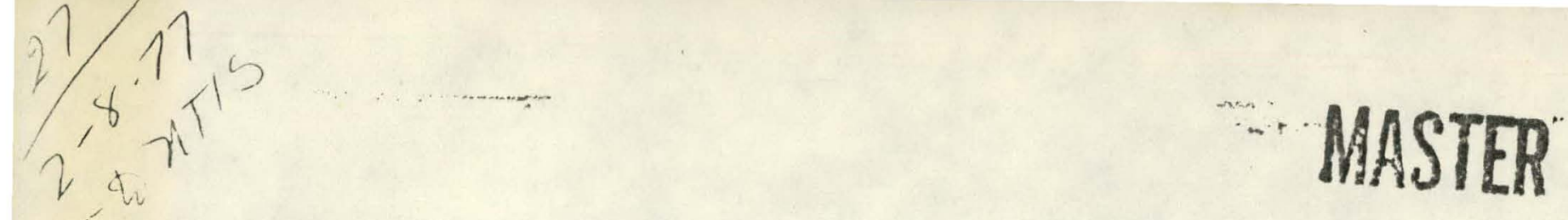

UCID- 17292

\section{Lawrence Livermore Laboratory \\ UCID--17292 \\ A80033702}

\section{SLIFERS REVISITED: A METHOD FOR DETERMINING YIELDS}

INDEPENDENT OF RADIOCHEMICAL MEASUREMENTS

J. T. Rambo

October 15, 1976

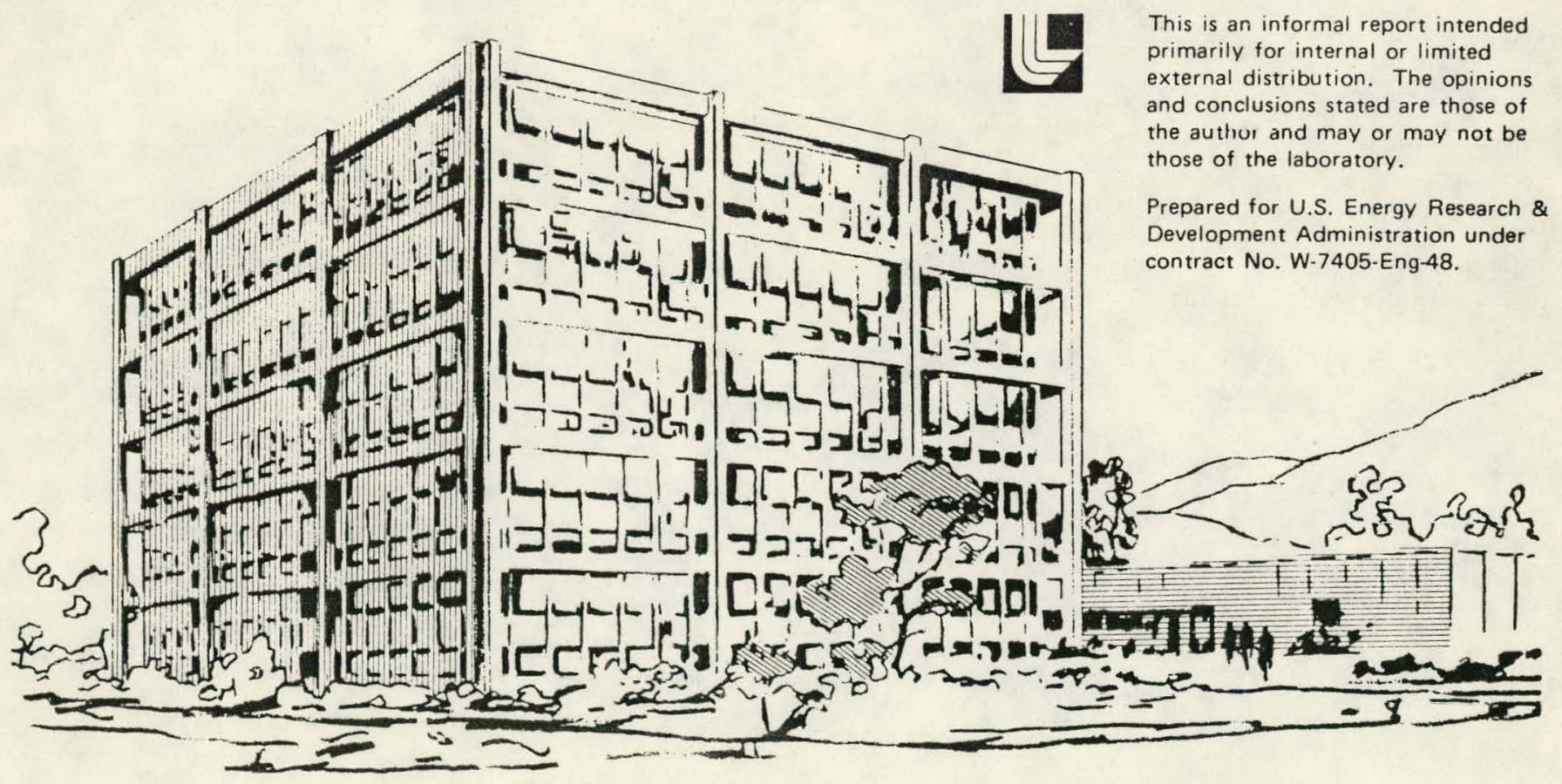


CONTENTS
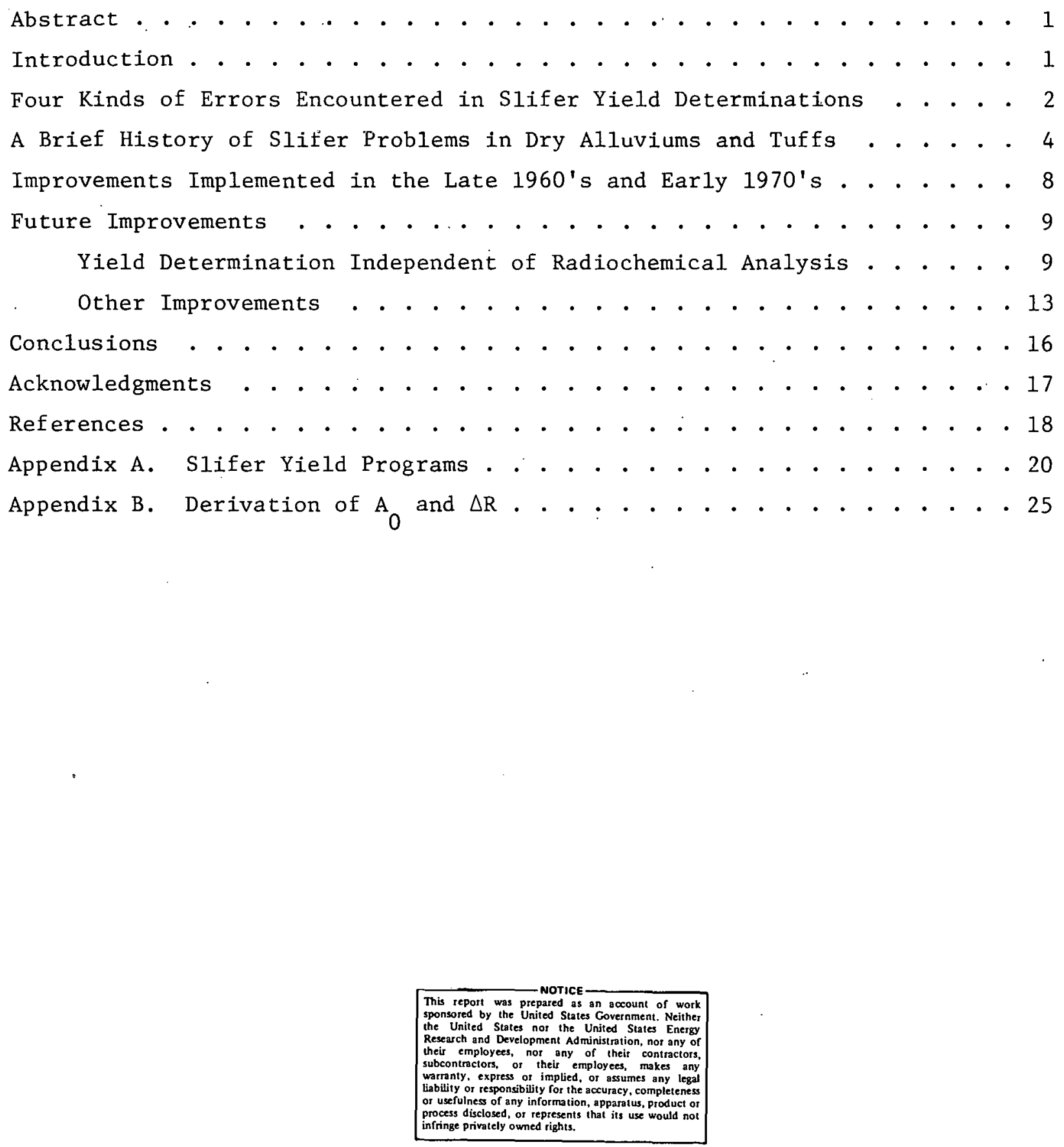


\title{
SLIFERS REVISITED: A METHOD FOR DETERMINING YIELDS INDEPENDENT
} OF RAD IOCHEMICAL MEASUREMENTS

\begin{abstract}
It would be very desirable if an independent method other than radiochemical measurement were available to determine the yields of low-yield events in the alluviums and tuffs of areas 2, 9, and 10 at the Nevada Test Site. The successful application of slifers to the measurement of yields from high-yield events suggests that under some conditions they may also be usable with lowyield events. This view is supported by the evidence discussed here, which is based on direct experience with slifer yield measurements for low-yield events in porous media. Suggested methods for improving slifer yield determinations and a method for determining yields independent of radiochemical measurements are offered.
\end{abstract}

\section{INTRODUCTION}

The attainment of reasonable success in using slifers to determine yields from high-yield events in areas 19 and 20 at the Nevada Test Site (NTS) has led to speculation about the usefulness of slifers in determining yields from low-yield events in the highly porous alluviums and tuffs of areas 2, 9, and 10. This report discusses some of the yield-determination problems that have already been experienced during lower-yield events in highly porous materials, and it suggests how they might be corrected. Alternative approaches are suggested to improve the yield-determination method. The ultimate goal is to determine yields without relying on radiochemical measurements. An example showing how this can be done is included.

The suggestions offered here are based on my experiences with LLL-N slifer measurements and yield reports involving porous materials during the period from 1963 through 1968. ${ }^{1-9}$ This experience has provided me with a number of valuable insights into the problems related to low-yield measurements in porous materials. Hopefully, the comments given here may help others to avoid some of the pitfalls encountered during earlier work in highly porous materials. 
FOUR KINDS OF ERRORS ENCOUNTERED IN SLIFER YIELD DETERMINATIONS

The basic premises in determining a yield using a slifer are that the geometry of the shock wave is spherical and that material properties are known well enough for comparisons to be made with a similar time-of-arrival

(TOA) data set. The data sets used may be in the form of a SOC74 calculation, 10 data from a previous event, or an average data set based on previous events or a strong-shock equation such as the BOTE mode1. 11

Four types of errors are involved in the use of slifers to determine yields:

\section{(1) Errors in Nonsphericity of the Wave}

Nonsphericity errors can be caused by material properties in the emplacement configuration leading to nonhomogeneous shock propagation rates. These arrivals can be observed at the boundaries of a device can or a line-of-site pipe, and in the emplacement hole stemming, which sometimes shows the shock ahead or behind the free-field shock measurement.

\section{(2) Errors in Late-Time Data}

As the shock wave runs later in time, it approaches asymptotically with time a nonreal, but apparent bulk sound speed $\left(A_{0}\right)$ given by the intercept of the shock speed/particle speed relationship.11-13 As shown in Fig. 1, the intercept is never reached because of a sudden change in slope caused by elastic phenomena or possibly a phase change. The major yield error encountered in late-time slifer data is in matching the $A_{0}$ of a new data set to $A_{0}$ of an averaged or calculated data set. Errors for late time were due to unknown intercepts and unknown changes in materlal properties.

\section{(3) Errors in Measurement Affecting Any or All Portions of the Data}

Measurement errors are due to (a) unknown vertical locations of the slifer instrument, (b) oscillator calibration errors caused by thermal drift, (c) satellite hole survey errors, (d) noise in the data, and (e) response time due to frequency limitations. All these errors are usually small compared lu. other errors.

\section{(4) Errors in the Analysis of Data}

Errors in analysis result from the need to (a) weight some data strongly or to throw other data out and (b) decide what corrections can be or need be made. These errors can be serious, and the methods that introduce them have oflen been arlitrary. 


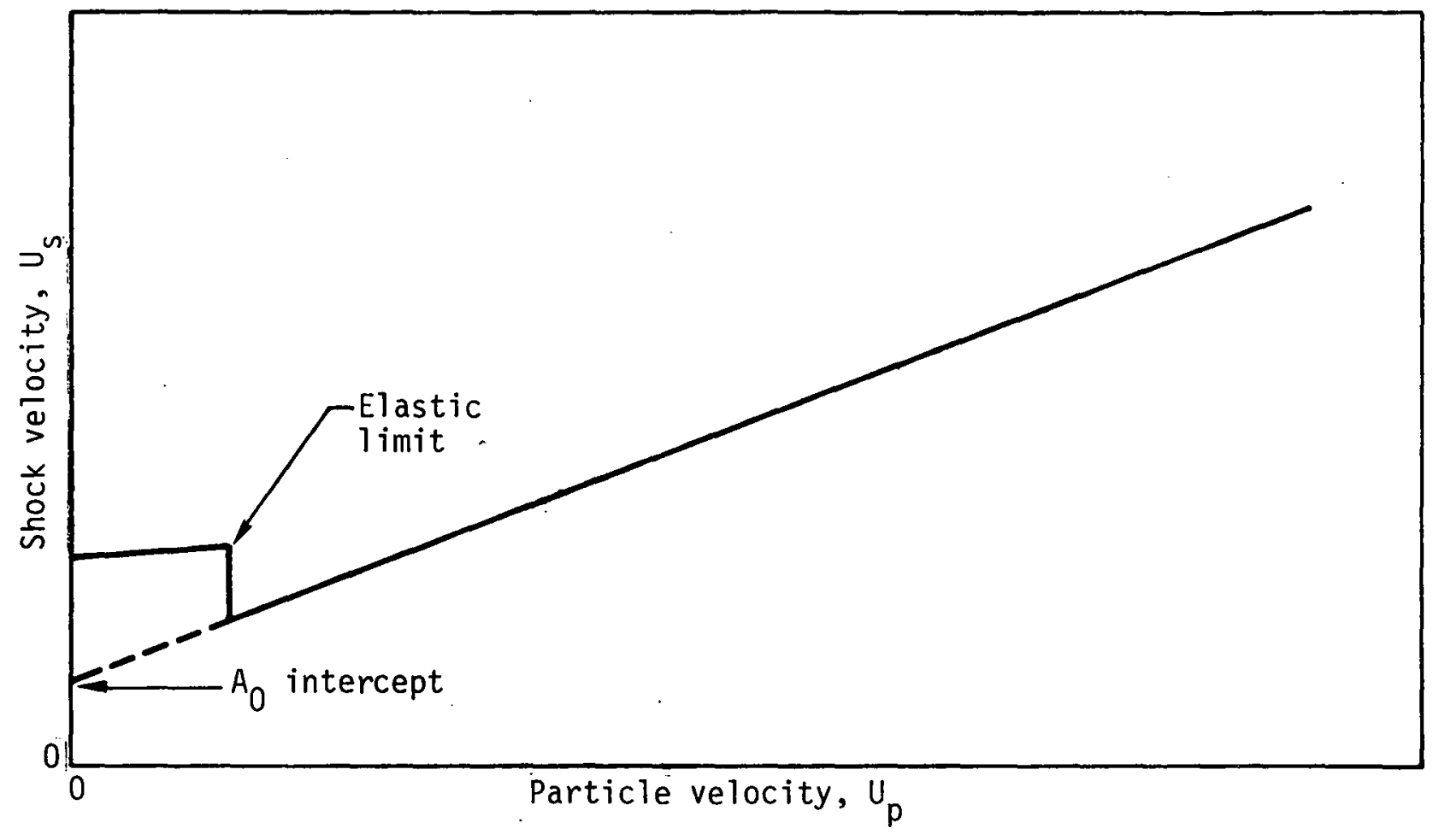

Fig. 1. The bulk sound speed shown as the intercept of the $U_{s}-U_{p}$ curve. 
With these errors in mind, we can now make a qualitative comparison between errors for high-yield events on Pahute Mesa and those for low-yield events in the NTS Flats area.

Error type 1, which deals with sphericity, is minimized on high-yield events, where in many cases the diagnostics can is within the vaporization radius and therefore has no effect on the wave shape. However, some small errors have been observed that result from the dry stemming, where shock in the stemming will travel at a different velocity than the ground shock.

Error type 2 is minimized on the Mesa at NTS by using only the close-in data, where $A_{0}$ intercepts have much less influence and where error 1 is minimal. Saturated materials below the water table tend to have similar Hugoniots at high stresses. It has been shown that air-filled porosity has the greatest effect on Hugoniots. 14

Error type 3 is negligible on the Mesa, where the oscillator cable locations are redundantly located and no satellite hole is needed.

Error type 4, analysis errors, is minimal if the other three errors are minimized. In the Flats, analysis was very difficult because of the presence of errors 1,2 , and 3 .

\section{A BRIEF HISTORY OF SLIFER PROBLEMS IN DRY ALLUVIUMS AND TUFFS}

In the early 1960's slifers were mainly used in emplacement holes, and diagnostic canisters were usually small. Most of the early development involved the reduction of instrument recording errors and development of oscillator emplacement techniques. Analysis was still black magic. Some yield reporls used the early-time data and other used the late-time data. The problem was really one of coming up with a reasonable fit at a respectable yield. The scaling method used was based on the diagram shown in Fig. 2.

The basic scaling equation is

$$
E_{x}=E_{s}\left[R_{x} / R_{s}\right]_{v}^{3}
$$

where $E$ is the yield, and subscripts $x$ and $s$ are the data and standard curves. Radius data (R) is scaled on a common $R / T$ line, which keeps the velocity ( $v$ ) constant. This equation assumes that the unknown curve has the same physical properties as the known, and that the shock wave is spherical. 


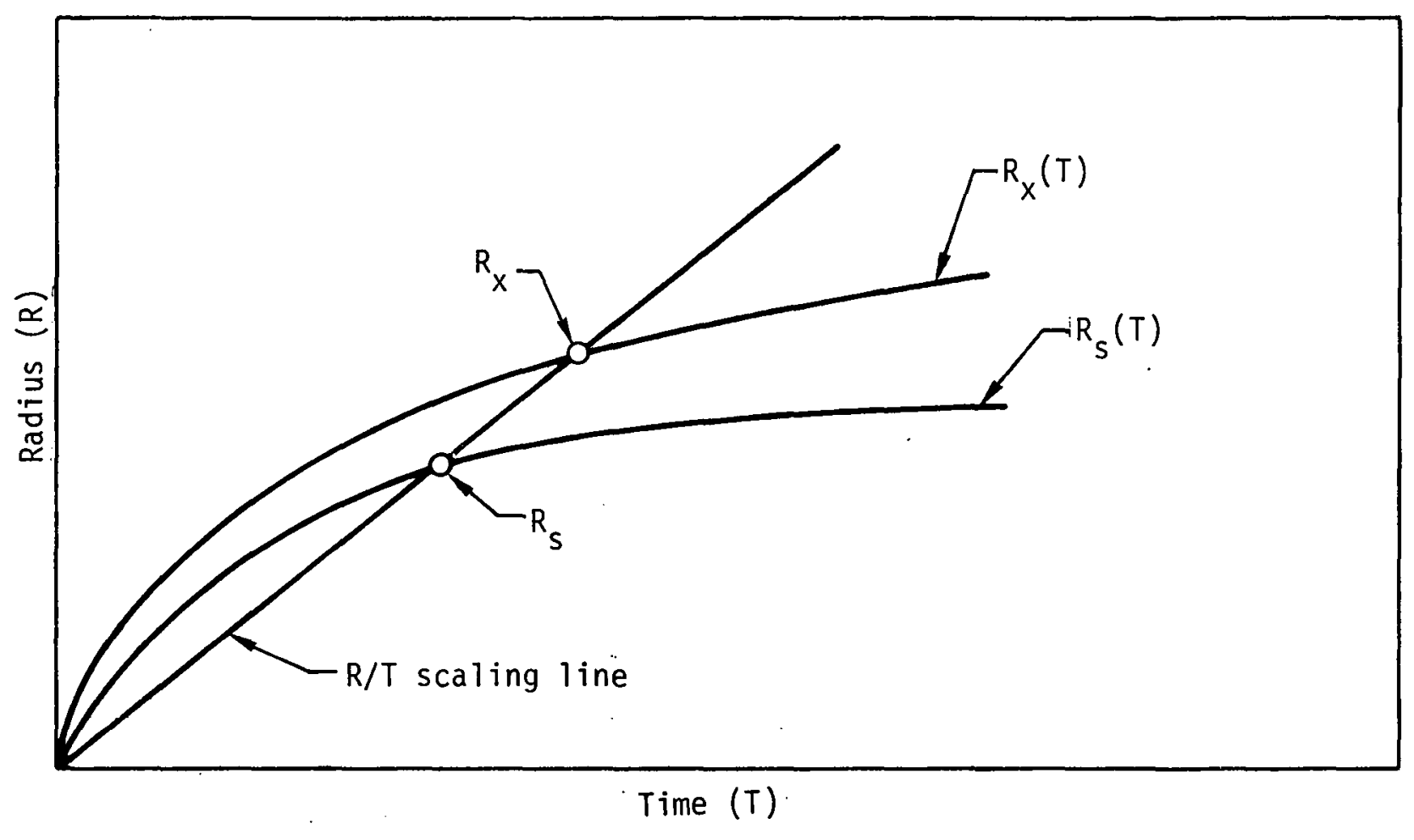

Fig. 2. Diagram on which Eq. 1, the scaling equation, was based. 
It was shown later (after 1970) ${ }^{11-13}$ that the strong shock form of the TOA curve fits the form

$$
R_{M}=E T^{2 / 5}+A_{0} T
$$

where $\Xi$, a function of energy (E) and $\gamma$, remains constant when $E$ and $\gamma$ are constant. The scaling equation we used from Eqs. 1 and 2 was then

$$
\left.E_{x}=E_{s}\left[\left(\Xi_{x} T_{x}^{2 / 5}+A_{0 x} T_{x}\right)\right) /\left(\Xi_{s} T_{s}^{2 / 5}+A_{0 s} T_{s}\right)\right]^{3}
$$

Note that the $A_{0} T$ terms are independent of energy. When $A_{0 x} \neq A_{0 s}$, this equation gives bad yields and is a large source of error at late times. I later showed $^{12,13}$ that the proper form is

$$
E_{x}=E_{s}\left[\left(R_{x}-A_{0 x} T_{x}\right) /\left(R_{s}-A_{0 s} T_{s}\right)\right]_{v}^{3}
$$

This form conforms to the blast-wave model proposed in part by myself in Refs. 12 and 13, and later by Kurtz in Ref. 11. This equation removes the $\mathrm{A}_{0}$ intercepts from late-time data. I will later show how $\mathrm{A}_{0}$ can be derived from the data itself, ${ }^{12,13}$ leading to an important correction in scaling error. Most of the slifer analysis using late-time data then has possibly serious errors (type 4). As can be seen in Fig. 3, $A_{0} T$ becomes the dominant term, and $\Xi \mathrm{T}^{2 / 5}$ approaches a constant at late times. Thus, the problem becomes worse with increasing time.

Slifer analysis has always had this problem of scaling to the $\mathrm{A}_{0} \mathrm{~T}$ values between curves. This is why Los Alamos Scientific Laboratory (LASL) and Sandia Laboratories later established curves for early-time data based on a fit

$$
\mathrm{R}=\mathrm{a}_{1} \mathrm{~T}^{\mathrm{a} 2}
$$

for $1 \mathrm{kt}$, when $a_{1}$ and $a_{2}$ are constants. It is easy to see that you can approximace the lusm of $\mathrm{Eq}$. 4 with $\mathrm{E}_{4} .2$ whon $A_{0} T$ is sma11, i.e.. $\mathrm{A}_{0} \mathrm{~T} \ll \mathrm{TT}^{2 / 5}$. Equation 4 is still is use.

However, close-in data from Eq. 4 could not be applied to slifer yields in the late 1960's, when low-yield shots with LOS diagnostics were common and matcrial properties were quite variable for late-time data. Slifer yields become very difficult to assess because of energy perturbations on close-in data from diagnostics. The eventual drilling and instrumenting of satellite 


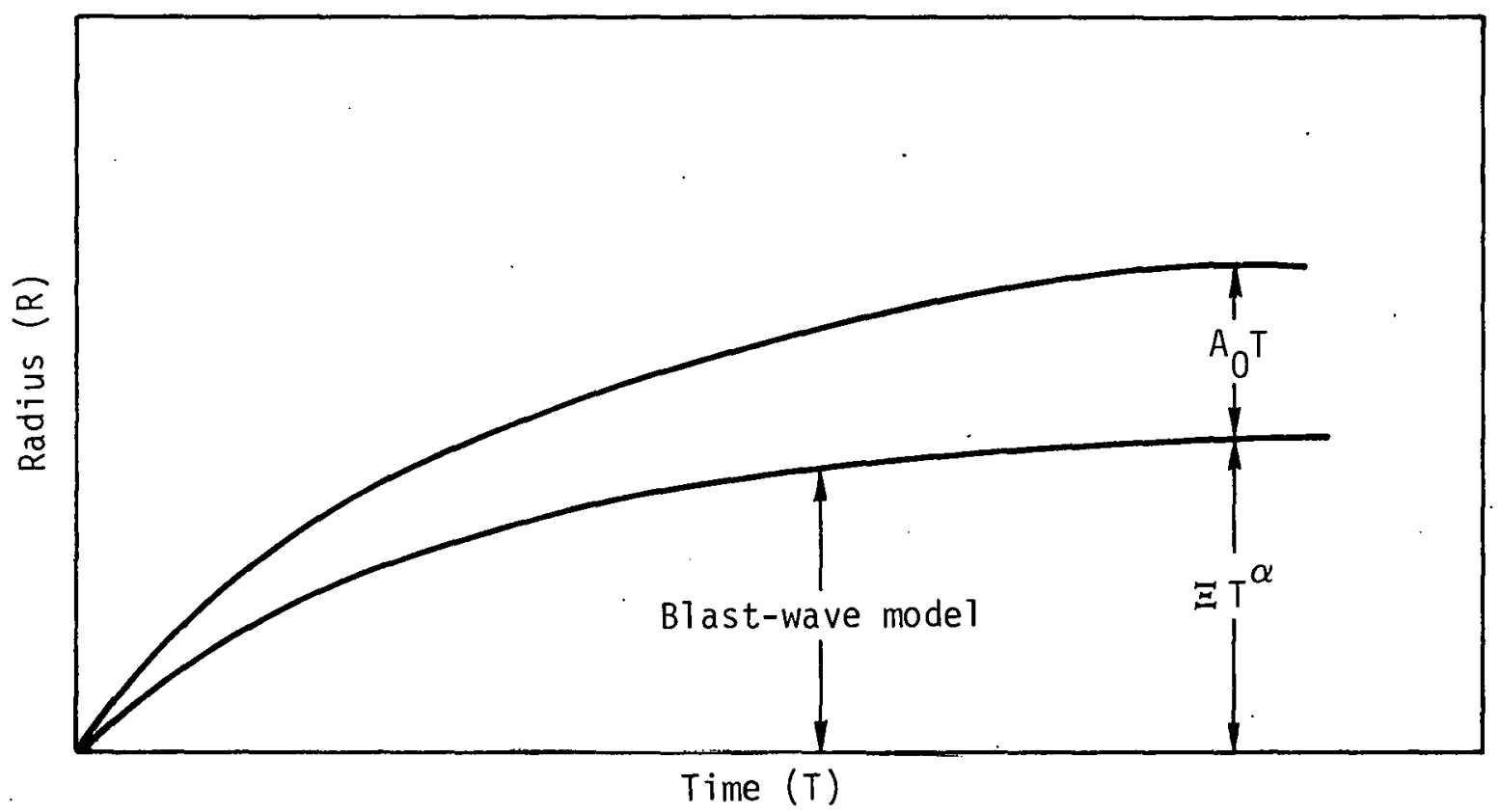

Fig. 3. Diagram showing how late-time data can produce serious errors. 
holes eliminated most of the problems associated with emplacement holes. This led to some improvement in center-of-energy measurements for the first TOA recorded horizontally from the device. However, a new problem was encountered that related to the accuracy of satellite hole surveys for hole-to-hole range measurements.

In summary, then, the errors in slifer yields arose from:

(1) Emplacement-hole stemming shock ahead of or behind ground shock.

(2) Emplacement-hole diagnostic cans and large LOS pipes.

(3) Very poor methods for comparing standard curves and data; arbitrary fits to either early- or late-time data. (No effective EOS method established.)

(4) Satellite hole surveys.

(5) Variability of medium properties through the shock-wave range of interest.

(6) No effective material properties measurements, i.e., $\rho_{0}$, wt\% $\mathrm{H}_{2} \mathrm{O}$, and $\rho_{g}$ for a total porosity; most density logs were poor.

(7) Improper use of the scaling equation for late-time data.

With these kinds of problems it is no wonder that we did poorly, i.e., $\pm 30 \%$ errors and sometimes $\pm 50 \%$ in these later years from 1965 to 1968 .

\section{IMPROVEMENTS IMPLEMENTED IN THE LATE 1960's AND EARLY 1970's}

The measurement of slifer data on each LLL event was terminared in about 1967 because of previously mentioned difficulties and the mounting cost of drilling satellite holes. Sandia-LASL concluded that only close-in data should be used on high-yield events where radiochemical methods could not give an accurate yield. LLL also accepted this position.

Implementing close-in yield measurements required that the energy center be well known, because errors in slifer locations for close-in measurements can cause serious yield errors. LLL realized that fitting TOA data to the apparent energy center was an important consideration. Corrections were made based on the first horizontal shock arrival in the satellite hole. For deep holes this method was somewhat constrained by horizontal survey accuracy and accuracy of vertical slifer oscillator emplacement.

Sandia-LASL has elected to shift the work point until a good fit is obtained on the data. This method is being used where no satellite hole is necessary. Although this approximation tends to be supported by the strongshock equation for close-in data, it has two flaws: (1) it dumps all the 
errors into a non-time-dependent, non-medium-dependent lump and (2) it does not make use of a better form of the basic scaling equation (Eq. 3) for the proper $\mathrm{A}_{0}$ correction.

Improvements were made in downhole surveying analyses that were applicable to satellite holes and hole-to-hole ranges. ${ }^{15}$ Two of these improvements were: (1) development of three-dimensional error ellipses for a surveyed downhole location based on number and location-of-survey points and tool accuracy $^{16}$ and (2) establishment of specifications and methods of implementing accurate downhole surveys. ${ }^{17}$ The most important factors are the type of tool used and survey station spacing. The comparison between survey error ellipses and actual measurement was established on Cannikin, for the downhole tunnel between UAl and UAldw. 18

In Ref. 17, I discussed at some length the survey methods, tool calibration, experience with survey companies, and different tools that improve survey accuracy.

Other improvements have been in slifer oscillator redesign and hardening, calibration techniques, ${ }^{19}$ digitization of slifer frequency by continuous period measurements, and, finally, L-Division's single-pass digitization with corrections for tape-speed errors. 20

At one point the slifer field system had been developed to give preliminary yields between $30 \mathrm{~min}$ and $1 \mathrm{~h}$ after the event.

\section{FUTURE IMPROVEMENTS}

\section{Yield Determination Independent of Radiochemical Analysis}

The goal of slifer yield determination should be to establish yield independent of reliance on radiochemical yield measurements, which are used to establish standard TOA curves. The following is a test case for this idea.

The energy equation that includes the intercept form is now accepted in the literature. ${ }^{11}$ This expression has two constants for material properties that can be used to convert to a Hugoniot. One is $A_{0}$, the $U_{s}$ intercept for the linear $U_{s}-U_{p}$ expression. The other is the Grüneisen constant $\gamma$, which in its limiting form is related to the slope $b$ of the $U_{S}-U_{p}$ relationship, i.e., $\gamma=2 b^{11}$. The equation is

$$
E=\rho_{0}\left(1.6010665 \times 10^{-8}\right)\left[\frac{(3 \gamma-1)}{(\gamma-1)(\gamma+1)^{2}}\right] \frac{\left(R_{m}+\Delta R-A_{0} T\right)^{5}}{T^{2}},
$$


where $E$ is total energy in $k t$,

$\mathrm{T}$ is arrival time in $\mu \mathrm{s}$,

$\rho_{0}$ is in $\mathrm{g} / \mathrm{cm}^{3}$,

$\mathrm{R}_{\mathrm{m}}$ is the radius in $\mathrm{cm}$ at arrival time $\mathrm{T}$,

$\gamma$ is a function of $\rho_{0}, \rho_{g}$, and $z$ from Ref. 11 ,

$\mathrm{A}_{0}$ is the intercept velocity in $\mathrm{cm} / \mu \mathrm{s}$ measured from data Eq. 8, and

$\Delta \mathrm{R}$ is an energy center correction in $\mathrm{cm}$ measured from data Eq. 7 .

As shown in Appendix $B$, the value of the intercept $A_{0}$ can be derived from two data points, $\left(\mathrm{R}_{1}, \mathrm{~T}_{1}\right)$ and $\left(\mathrm{R}_{2}, \mathrm{~T}_{2}\right)$, and Eq. 2:

$$
A_{0}=\frac{\left(T_{2} / T_{1}\right)^{2 / 5} R_{1}-R_{2}}{\left(T_{2} / T_{1}\right)^{2 / 5} T_{1}-T_{2}}
$$

$\Delta \mathrm{R}$, the correction for energy-center location for which LASL used a statistical method, can now be derived from three or four TOA points. The three-point method is:

$$
\begin{aligned}
\Delta R & =\left[\frac{\left(\mathrm{T}_{3} / \mathrm{T}_{2}\right)^{2 / 5} \mathrm{R}_{2}-\mathrm{R}_{3}}{\left(\mathrm{~T}_{3} / \mathrm{T}_{2}\right)^{2 / 5} \mathrm{~T}_{2}-\mathrm{T}_{3}}-\frac{\left(\mathrm{T}_{2} / \mathrm{T}_{1}\right)^{2 / 5} \mathrm{R}_{1}-\mathrm{R}_{2}}{\left(\mathrm{~T}_{2} / \mathrm{T}_{1}\right)^{2 / 5} \mathrm{~T}_{1}-\mathrm{T}_{2}}\right] \\
& \div\left[\frac{\left(\mathrm{T}_{2} / \mathrm{T}_{1}\right)^{2 / 5}-1}{\left(\mathrm{~T}_{2} / \mathrm{T}_{1}\right)^{2 / 5} \mathrm{~T}-\mathrm{T}_{2}}-\frac{\left(\mathrm{T}_{3} / \mathrm{T}_{2}\right)^{2 / 5}-1}{\left(\mathrm{~T}_{3} / \mathrm{T}_{2}\right)^{2 / 5} \mathrm{~T}_{2}-\mathrm{T}_{3}}\right]
\end{aligned}
$$

$A_{0}$ derived from two TOA points and $\triangle \mathrm{R}$ is:

$$
\mathrm{A}_{0}=\frac{\left(\mathrm{T}_{2} / \mathrm{T}_{1}\right)^{2 / 5} \mathrm{R}_{1}-\mathrm{R}_{2}}{\left(\mathrm{~T}_{2} / \mathrm{T}_{1}\right)^{2 / 5} \mathrm{~T}_{1}-\mathrm{T}_{2}}+\frac{\left[\left(\mathrm{T}_{2} / \mathrm{T}_{1}\right)^{2 / 5}-1\right] \Delta \mathrm{R}}{\left(\mathrm{T}_{2} / \mathrm{T}_{1}\right)^{2 / 5} \mathrm{~T}_{1}-\mathrm{T}_{2}}
$$

Finally, $\gamma$ is a derivable parameter based on material properties ( $\rho_{0}$, $\left.\rho_{g}, Z\right) .^{11}$ These are currently being measured or estimated for every event. The implication is that the energy equation should work for radius-time slifer data that have constant $A_{0}, \gamma, \Delta R$, and $\rho_{0}$ over the TOA data range. 


\section{Test Case No. 1}

I ran a test case for the Camembert event for what I would expect to be a good set of data. The procedure was as follows: I scaled the Camembert data set (see Table 1 ) to $1 \mathrm{kt}$ based on the radiochemistry yield result and plotted radius vs $\mathrm{T}^{2 / 5}$, as shown in Fig. 4. I selected three fairly evenly time-spaced TOA points (shown with circular symbols). I used three points to derive $\Delta R$ and $A_{0}$ through Eqs. 6 and 7 . The result was $A_{0}=0.1655 \mathrm{~cm} / \mu \mathrm{s}$ and $\Delta \mathrm{R}=13.704 \mathrm{~cm}$. The data corrected for $\mathrm{A}_{0}$ then gave a reasonably good linear fit to all the data, as shown in Fig. 4. Then $\gamma$ was derived from Kurtz's BOTE model ${ }^{11}$ using the reported physical property values $\rho_{0}=2.21 \mathrm{~g} / \mathrm{cm}^{3}$, $\rho_{g}=2.6 \mathrm{~g} / \mathrm{cm}^{3}$, and $z=0.11029 .^{21}$ The resulting value for $\gamma$ was 1.5807 . The three points gave a result of $0.945 \mathrm{kt}$. The average yield for all the data was $0.985 \mathrm{kt}$. This represents a yield completely independent of radiochemical results. A copy of the data and of two Hewlett-Packard HP-65 programs that you can use to run this problem are given in Appendix A. These are included to allow those who are interested to test them. It is also instructive to see how easily other sets of three points can give different results. The implication is that data noise or changing $A_{0}$ and $\gamma$ can render useless yield results. The three points selected represent a method of averaging the data. Other methods now used by $C$. Olsen essentially do the same thing with a regression fit to the data. 22

\section{Test Case No. 2}

A second set of TOA data was taken from a SOC74 run on the same event as in test case 1 . The Hugoniot was derived from measured phýsical propertics via the Butkovich model, ${ }^{23}$ and the same yield was used to generate the TOA data. The $\mathrm{P}-\mu$ data were converted to the $\mathrm{U}_{s}-\mathrm{U}_{\mathrm{p}}$ curve shown in Fig. 5. This. $U_{s}-U_{p}$ relationship shows not a straight line, but one that dramatically curves downward with decreasing particle velocity.

Computing $\mathrm{A}_{0}$ and $\triangle \mathrm{R}$ from data in Table 2 gave results for $\mathrm{A}_{0}$ that agreed reasonably well with the part of the $U_{S}-U_{p}$ line represented by the SOC TOA data. The $\Delta R$, calculation gave very large $\Delta R$ values, which resulted in erroneous yield values in the energy equation. These results indicate that ( 1 ) derived $A_{0}$ give a reasonable average through the three points taken, and (2) the $\Delta R$ calculation indicates a true $\Delta \mathrm{R}$ or the $\mathrm{U}_{\mathrm{S}}{ }^{-\mathrm{U}} \mathrm{p}$ relationship has curvature or discontinuity within the three test points. This can be used to decide 


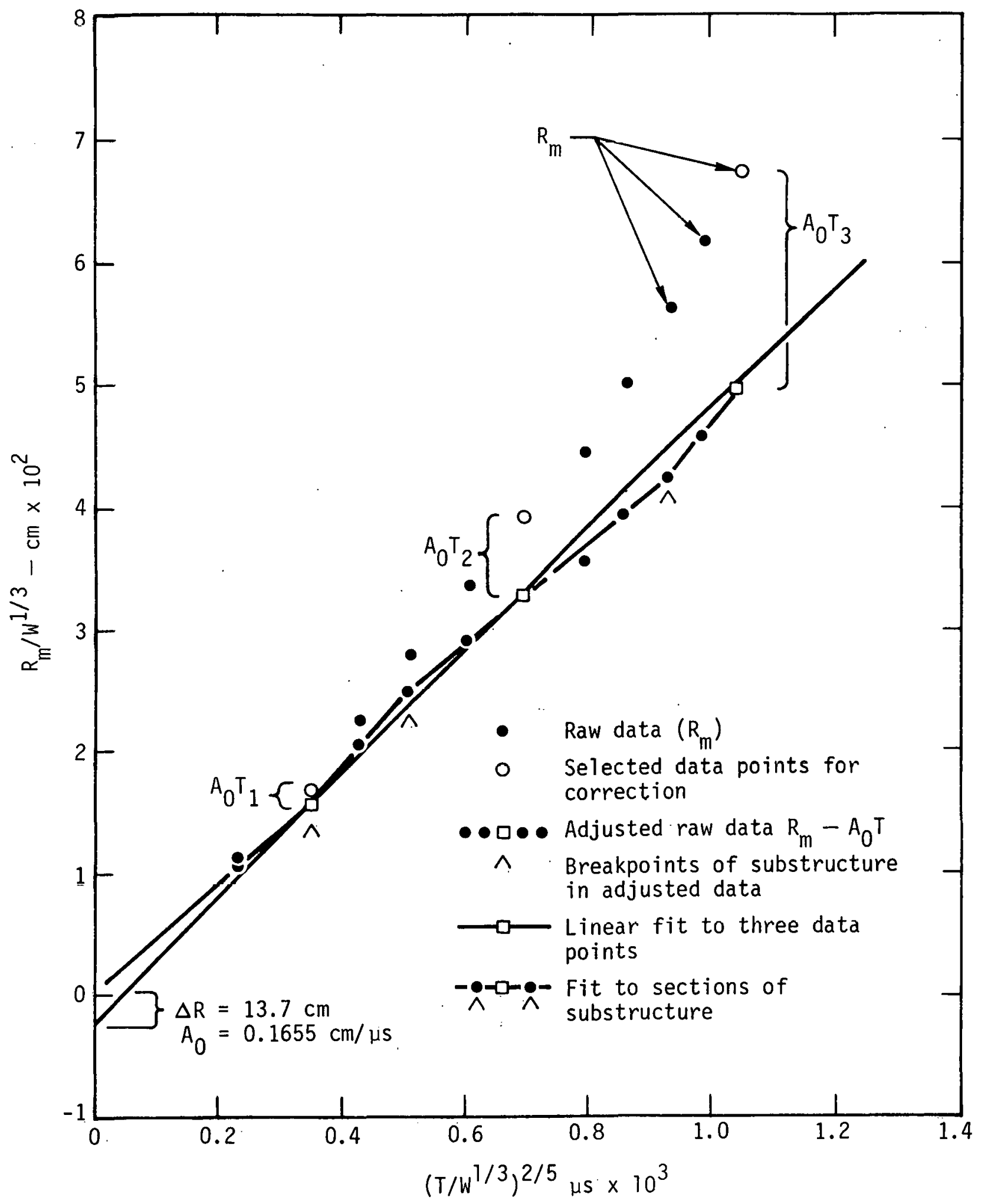

Fig. 4. Plot of radius vs $\mathrm{T}^{2 / 5}$ made for test case No. 1 . 
Table 1. Example of usable data - Camembert slifer data.

\begin{tabular}{cccc}
\hline & $\begin{array}{c}\mathrm{R}_{\mathrm{m}} / \mathrm{W}^{1 / 3} \\
(\mathrm{~cm})\end{array}$ & $\mathrm{T} / \mathrm{W}^{1 / 3}$ & $\mathrm{~W}$ \\
$\mathrm{~N}$ & 112.09 & $(\mathrm{ks})$ & 1.1389 \\
\hline 1 & 168.14 & 28.0 & 0.9439 \\
$2^{\mathrm{a}}$ & 224.19 & 71.7 & 1.0946 \\
3 & 280.23 & 123.3 & 1.2862 \\
4 & 336.28 & 183.8 & 1.1236 \\
5 & 392.33 & 280.2 & 0.9439 \\
$6^{\mathrm{a}}$ & 448.37 & 403.5 & 0.7983 \\
7 & 504.42 & 549.3 & 0.8144 \\
8 & 560.47 & 679.3 & 0.8302 \\
9 & 616.51 & 818.3 & 0.9067 \\
10 & 672.56 & 947.2 & 0.9439 \\
$11^{\mathrm{a}}$ & & 1092.9 & \\
\hline
\end{tabular}

${ }^{a}$ Using points $2,6,11$ and Eqs. 6 and 7 gives $A_{0}=0.165512 \mathrm{~cm} / \mu \mathrm{s}$ and $\Delta \mathrm{R}=13.7043 \mathrm{~cm}$.

if this yield method should be used or to determine the proper data to be used for yield determination.

Some other ideas have occurred to me that could be fruitful. There is possibly some equation or numerical method that would allow the continuous derivation of $\gamma$ as well as $A_{0}$ through the whole set of data. I think this would be a useful area of investigation. Conversely, if the total energy is known, then $\gamma$ and ultimately $\mathrm{P}-\mu$ can be measured from the data.

Other Improvements

Several addicional improvements are suggesced below:

(1.) Systematic errors due to scaling TOA curves of diverse properties can be factored out. If, for example, $\gamma$ is not available for the energy equation, then a TOA curve of suspected similar properties may be scaled to the data TOA curve with reduced error. Since $A_{0}$ can be measured on each curve, both can be factored out of the data when scaling the data with Eq. 3 . An example of this is demonstrated in Ref: $13, \therefore$ where alluvium is scaled to granite. 


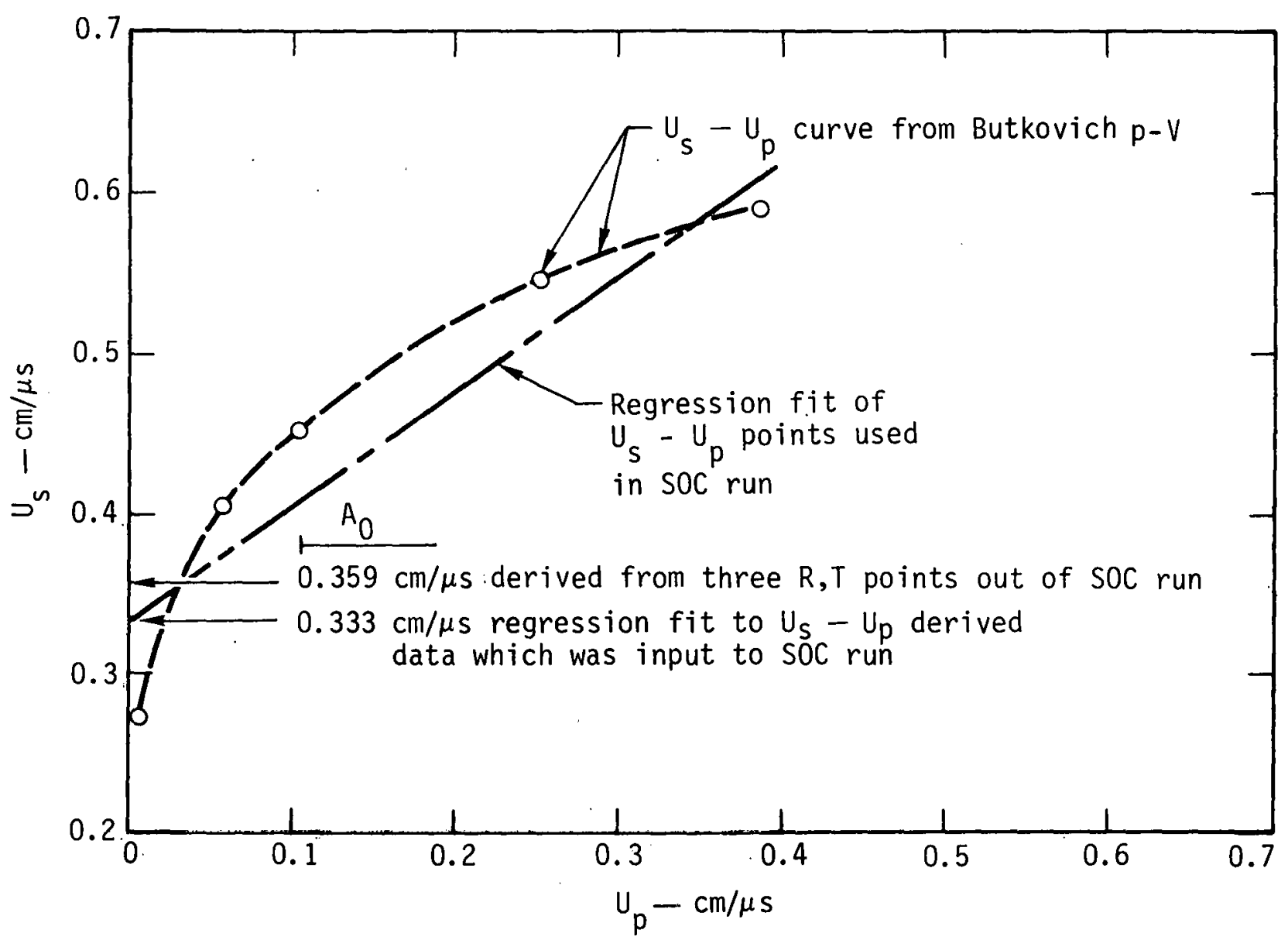

Fig. 5. A A derived from input to SOC74 compared with $A_{0}$ derived from output $\mathrm{R}, \mathrm{T}$ of the SOC74 run. The agreement indicates that $\mathrm{A}_{0}$ derived from three $\mathrm{R}, \mathrm{T}$ points gives good average values over the portion of the Hugoniot repreoented by the three points. 
Table 2. Example of unusable data - Camembert SOC74 data.

\begin{tabular}{cccc} 
& $\begin{array}{c}\mathrm{R}_{\mathrm{m}} / \mathrm{W}^{1 / 3} \\
(\mathrm{~cm})\end{array}$ & $\begin{array}{c}\mathrm{T} / \mathrm{W}^{1 / 3} \\
(\mu \mathrm{s})\end{array}$ & $\begin{array}{c}\mathrm{W} \\
(\mathrm{kt})\end{array}$ \\
\hline $1^{\mathrm{a}}$ & 196.28 & 69.5 & 0.0464 \\
2 & 230.58 & 112.8 & 0.0445 \\
3 & 303.89 & 224.6 & 0.04164 \\
4 & 370.13 & 337.3 & 0.04208 \\
5 & 432.68 & 448.6 & 0.04443 \\
$6^{\mathrm{a}}$ & 493.10 & 561.5 & 0.0464 \\
7 & 550.72 & 673.2 & 0.04795 \\
8 & 608.11 & 785.6 & 0.05034 \\
9 & 664.71 & 897.6 & 0.05318 \\
10 & 716.50 & 1010.4 & 0.05176 \\
11 & 766.61 & 1142.2 & 0.04257 \\
$12^{\mathrm{a}}$ & 864.35 & 1347.4 & 0.0464 \\
\hline
\end{tabular}

${ }^{\mathrm{a}}$ Using points $1,6,12$ gives $\mathrm{A}_{0}=0.35936 \mathrm{~cm} / \mu \mathrm{s}$ and $\Delta \mathrm{R}=-79.44 \mathrm{~cm}$.

This procedure should be used when scaling any two curves, and this is one of my objections to the trial-and-error work point shift method used by LASL and Sallidia.

(2) Geophysical properties for slifer sites should emphasize the zone where slifer cables are placed. The most important properties are $\rho_{0}$, $\rho_{g}$, and $z$. From these a value of $\gamma$ can be derived for an independent energy measurement.

(3) A useful Hugoniot could be obtained below the water table. The Bulkuvich model ${ }^{23}$ for oaturated materials bel nw the water table has been shown to give excellent results for TOA and peak values of the plastic wave out to very late times and radii. Data from Handley and Flax support this. ${ }^{24,25}$ It would be of some advantage to fire a low-yield event with error-producing diagnostics helow the water table. This reduces variations due to air-filled porosity by filling all the void space with water, and it increases ground shock velocity away from diagnostic problems. The many variations and 
combinations of water and rock present less abrupt changes in the shock-wave velocity $^{14}$ and are accurately predicted from the Butkovich model or. BOTE model. An added advantage is that the saturated shock-wave will travel for greater distances at higher stress, thereby rendering more data.

(4) An understanding could be acquired of the limitations of slifer use by the application of new techniques on existing slifer data. The existing slifer data in the flats contains a wide variety of encountered problems. It would be appropriate to review this data and check it for an independent energy measurement as suggested above. I have looked at some of this data in Ref. 2 and found that if the medium is reasonably homogeneous, excellent linear fits to $\mathrm{R}_{\mathrm{m}}=\Xi \mathrm{T}^{2 / 5}+\mathrm{A}_{0} \mathrm{~T}$ can be obtained.

The raw data have gradually been deteriorating with time; these data represents in total, several million dollars worth of effort. These and other slifer data need to be located systematically and digitized. Records should be kept on surveys, calibrations, corrections made, etc.

\section{CONCLUSIONS}

The history of slifer yield measurements and the ensuing problems has emphasized corrections mostly in the area of hardware and spherical geometry corrections (errors 3 and 1 ). I believe that further work in this area, although useful, will give diminishing results for the effurt. I believe that error reduction is to be achieved primarily through the analysis and incorporation of such medium characteristics as those used in the BOTE model.

The goal, of course, is to develop independence from radiochemistry for yield calculations. An example of this was demonstrated for Camembert. Development needs to be done on methods for identifying erroneous data and using late-time data with software techniques based on the strong-shock equation shown here. Much of this could be tested on existing data for porous alluviums and tuffs. The question yet to be answered is, how small a yield and how large a perturbation of a spherical wave will the free field measurement sustain and still give some valid yield results. The payoff of independent yield measurements for a nuclear test is probably worth this effort.

A method of obtaining continuous $\gamma, A_{0}$ derivations from TOA data needs to be looked at with SOC. The problem of test case two may be solvable with the right methods. This would allow the derivation of energy through multiple 
mediums with variable properties. One important application would be the derivation of P- $\mu$ data from TOA data and a known energy.

The application value of the methods given here is significant. They employ a first step in actually interpreting the data according to criteria rather than the present method of blindly matching data for a good fit. A method of extending yield measurements to late-time data is given by Eq. 3 and Ref. 13. This method must be employed if slifers are to be used with long device cans or LOS measurements.

A method of $\mathrm{P}-\mu$ measurement has been suggested that, if employed, would have significant application value for containment calculations.

The usefulness of an independent slifer yield for the Nuclear Test Program is obvious.

\section{ACKNOWLEDGMENTS}

I wish to acknowledge the helpful comments and corrections provided by Stephan R. Kurtz and Robert W. Terhune during the preparation of this report. 


\section{REFERENCES}

1. J. T. Rambo, Hydrodynamic Yield - Fade Event, U9be, Apriz 26, 1965, Lawrence Livermore Laboratory unnumbered report (1965).

2. J. T. Rambo, Hydrodynomic Yield.-Forest Event, U7a, January 12, 1965, Lawrence Livermore Laboratory unnumbered report (1965).

3. J. T, Rambo, Hydrodynomic Yield - Unannounced Event, December 15, 1965, Lawrence Livermore Laboratory unnumbered report (1965).

4. J. T. Rambo, Hydrodynamic Yield - Par Event, March 18, 1965, Lawrence Livermore Laboratory unnumbered report (1965).

5. J. T. Rambo, Hydrodynamic Yield - Unannounced Event, September 28, 1965, Lawrence Livermore Laboratory unnumbered report (1965).

6. J. T. Rambo, Hydrodynamic Yield-Centaur Event, May 17, 1966, Lawrence Livermore Laboratory unnumbered report (1966).

7. J. T. Rambo, Hydrodynamic Yiezd - Cup Event, July 26, 1965, Lawrence Livermore Laboratory unnumbered report (1965).

8. J. T. Rambo, Hydrodynomic Yiezd - Tweed Event, June 25, 1965, Lawrence Livermore Laboratory unnumbered report (1965).

9. J. T. Rambo, Hydrodynamic Yield-Clymer Event, May 16, 1966, Lawrence Livermore Laboratory report CN-TGD-1313 (1966).

10. C. M. Snell, User's Manual for SOC74, Rev. 2, Lawrence Livermore Laboratory report RKCD. 76-12 (1976).

11. S. R. Kurtz, J. Geophys. Res. 80 (32), 4449 (1975).

12. J.. T. Rambo, Preliminary Analysis of Tayzor Wave Applications of Ground Shock.s, Lawrence Livermore Laboratory Report UOPKB 71-121 (1971).

13. J. T. Rambo, Density Ratios Applied to Scaling and a New Scaling Method, Lawrence Livermore Laboratory Report UOPKB 72-7 (1972).

14. B. K. Crowley, Effects of Porosity and Saturation of Shock Wave Response in Tuffs, Lawrence Livermore Laboratory Report UCRL-74207 (1972).

15. J. R. Hearst, Updating of GORBAG: a Code for Calculating Range Between Two Hol.es, and for Slifer Analysis, Lawrence Livermore Laboratory Report UOPKL 68-56 (1968).

16. J. T. Rambo, UAI and UA1-dw Survey Locations and Accuracies, Lawrence Livermore Laboratory. :Report UOPKB-71-10 (1971).

17. J. T. Rambo, Rio Blanco Directional Surveys to Date and Error Predictions to Lowest Detonation Center, Lawrence Livermore Laboratory Report UCON 74-51 (1974). 
18. J. T. Rambo, Subsurface Directional Survey Error Code and Its Application to the UA1 and UA1-dw Cased Hole Survey, Lawrence Livermore Laboratory Report UOPKB 71-25 (1971).'

19. J. T. Rambo, New Slifer Calibration Subroutine for GORBAG (LSFIT), Lawrence Livermore Laboratory Report UOPK 69-29 (1969).

20. H. F. Finn, GORBAG 1974, Lawrence Livermore Laboratory Report UCID-16505 (1974).

21. N. W. Howard and H. L. McKague, Site Characteristics Summary, U19q, Update, Lawrence Livermore Laboratory Report UOPKB 75-50 (1975).

22. C.'W. Olsen, private communication (1975).

23. T. R. Butkovich, A Technique for Generating Pressure-Volume Relationships and Failure Envelopes for Rocks, Lawrence Livermore Laboratory Report UCRL-51441 (1973).

24. J. T. Rambo and R. W. Terhune, SOC Calculations of Handley, Lawrence Livermore Laboratory Report UCON 74-55 (1974).

25. J. T. Rambo and R. W. Terhune, SOC Comparison Runs, A Progress Report, Rev. 1, Lawrence Livermore Laboratory Report UCON 73-23 (1973). 
APPENDIX A

HP-65 PROGRAMS FOR SLIFER YIELDS

$-20-$ 
Table A-1. Program 1 for slifer yield, $A_{0}$, and $\Delta \mathrm{R}$ determination. 12,13

\begin{tabular}{|c|c|c|c|c|c|c|}
\hline $\begin{array}{l}\text { Key } \\
\text { entry }\end{array}$ & $\begin{array}{l}\text { Code } \\
\text { shown }\end{array}$ & Comments & $\begin{array}{l}\text { Key } \\
\text { entry }\end{array}$ & $\begin{array}{l}\text { Code } \\
\text { shown }\end{array}$ & Comments & Registers: \\
\hline LBL & 23 & . & 9 & 09 & 1 & $R_{3}$ \\
\hline A & 11 & & $\div$ & 81 & $L$ & \\
\hline$f^{-1}$ & 32 & & sto & 33 & & $\mathrm{R}_{2}: \mathrm{T}_{1}$ \\
\hline $\mathrm{SF} 1$ & 51 & Set flag to ofF & + & 61 & & $\left(\mathrm{~T}_{2} / \mathrm{T}_{1}\right)^{0.4}$ \\
\hline$f$ & 31 & & 4 & 04 & & $\left(\mathrm{~T}_{3} / \mathrm{T}_{2}\right)^{0.4}$ \\
\hline REG & 43 & & $\mathrm{RCL} 2$ & 3402 & & \\
\hline $\mathrm{R} / \mathrm{S}$ & 84 & Enter $R_{1}(\mathrm{~cm})$ & RCL 6 & 3406 & Shift data locations & $\mathrm{R}_{3}: \mathrm{R}_{2}$ \\
\hline STO 1 & 3301 & & STO 2 & 3302 & before looping to $B$ & \\
\hline $\mathrm{R} / \mathrm{S}$ & 84 & Enter $\mathrm{T}_{1}(\mu \mathrm{s})$ & $\mathrm{R} \downarrow$ & 3508 & & $\mathbf{R}_{4}: \quad \Sigma Q_{1,2}, Q_{2,3}$ \\
\hline STO 2 & 3302 & & STO 6 & 3306 & & \\
\hline$R / S$ & 84 & Enter $R_{2}(\mathrm{~cm})$ & RCL 8 & 3408 & & $R_{5}: \quad \Sigma w_{1,2}, w_{2,3}$ \\
\hline Sто 3 & 3303 & & RCL 8 & 3408 & ${ }^{\circ}$ & . \\
\hline $\mathrm{R} / \mathrm{S}$ & 84 & Enter $\mathrm{T}_{2}(\mu \mathrm{s})$ & STO 8 & 3308 & & $\mathbf{R}_{6}: \mathrm{T}_{3}$ \\
\hline sto 7 & 3307 & & $R+$. & 3508 & & $\left(\mathrm{~T}_{2} / \mathrm{T}_{1}\right)^{0.4}$ \\
\hline $\mathrm{R} / \mathrm{S}$ & 84 & Enter $R_{3}(\mathrm{~cm})$ & STO 1 & 3301 & & \\
\hline STO 8 & 3308 & & $f$ & 31 & & $R_{7}: T_{2}$ \\
\hline $\mathrm{R} / \mathrm{S}$ & 84 & Enter $\mathrm{T}_{3}(\mu \mathrm{s})$ & TF1 & 61 & & \\
\hline sto 6 & 3306 & & GTo & 22 & . & $\mathrm{R}_{8}: \mathrm{R}_{3}$ \\
\hline T.BT. & 23 & & $\mathrm{p}$ & 14 & - & $\mathrm{R}_{1}$ \\
\hline B & 12 & & 1 & 01 & & $\mathrm{R}_{9}:\left(\mathrm{T}_{2} / \mathrm{T}_{1}\right)^{0.4} \mathrm{~T}_{1}-\mathrm{T}_{2}$ \\
\hline RCL 7 & 3407 & & CHS & 42 & & \\
\hline RCL 2 & 3402 & & sto & 33 & ' & \\
\hline$\div$ & 81 & & $x$ & 71 & & Labels: \\
\hline$\cdot$ & 83 & & 4 & 04 & & \\
\hline 4 & 04 & & STo & 33 & & A start \\
\hline g & 35 & & $x$ & 71 & & B int. 10op \\
\hline$y^{x}$ & 05 & & 5 & 05 & & D final calc. \\
\hline RCL 2 & 3402 & & $f$ & 31 & & \\
\hline$x \neq y$ & 3507 & & SF1 & 51 & Set flag to oN & Flags: \\
\hline STо 2 & 3302 & & Gто & 22 & Next pass will go to $D$ & \\
\hline$x$ & 71 & & в & 12 & & 1 on $\rightarrow$ label $D$ \\
\hline RCL 7 & 3407 & & LBL & 23 & & off $\rightarrow$ label B \\
\hline- & 51 & & $\mathrm{D}$ & 14 & & \\
\hline sто & 33 & & $\mathrm{R} \uparrow$ & 3509 & & \\
\hline 9 & 09 & & $\mathrm{R} \uparrow$ & 3509 & - & \\
\hline RCL 2 & 3402 & $\Gamma$ & $\operatorname{RCL} 4$ & 3404 & $a_{j_{3}}-a_{1}$ & \\
\hline 1 & 01 & & RCL 5 & 3405 & $\Delta R=\frac{1,3}{W_{1,2}-1,2}$ & \\
\hline- & 51 & $W_{1,2}=\left(T_{2} / T_{1}\right)^{0.4}-1$ & $\div$ & 81 & $L^{1,2} 2,3$ & \\
\hline RCL & 34 & $1,2 \quad \overline{\left(\mathrm{T}_{2} / \mathrm{T}_{1}\right)^{0.4} \mathrm{~T}_{1}-\mathrm{T}_{2}}$ & $\mathrm{R} / \mathrm{S}$ & 84 & Display $\Delta R(\mathrm{~cm})$ & \\
\hline 9 & 09 & & STo 8 & 3308 & & \\
\hline$\div$ & 81 & and $w_{2,3}=\ldots$ loop 2 & RCL 6 & 3406 & $\Gamma$ & \\
\hline STo & 33 & & 1 & 01 & & \\
\hline- & 51 & & - & 31 & & \\
\hline 5 & 05 & & $x$ & 71 & $0.4-$ & \\
\hline RCL 2 & 3402 & $r$ & $\mathrm{KCL}$ & $34 \cdot$ & $A_{0}=a_{1,2}+\frac{\left[\left(T_{2} / T_{1}\right)\right.}{\left.\left(T_{2} / T_{2}\right)^{0.4} T_{1}-1\right] \Delta R}$ & \\
\hline RCL 1 & 3401 & $=\left(\mathrm{T}_{2} / \mathrm{T}_{1}\right)^{0.4} \mathrm{R}_{1}-\mathrm{R}_{2}$ & 9 & 09 & & . \\
\hline$x$ & 71 & ${ }_{1,2}=\overline{\left(T_{2} / T_{1}\right)^{0.4} T_{1}-T_{2}}$ & $\div$ & 81 & & \\
\hline RCL 3 & 3403 & & + & 61 & & \\
\hline- & 51 & & STo 2 & 3302 & L & \\
\hline RCL & 34 & and $a_{2,3}=\ldots$ loop 2 & $\mathrm{R} / \mathrm{S}$ & 84 & Display $A_{0}(\mathrm{~cm} / 1 \mathrm{~s})$ & \\
\hline
\end{tabular}


Table A-2. Program 2 for slifer yield, $\gamma,{ }^{23}$ and yield determination.

\begin{tabular}{|c|c|c|c|c|c|c|}
\hline $\begin{array}{l}\text { Key } \\
\text { entry }\end{array}$ & $\begin{array}{l}\text { Code } \\
\text { shown }\end{array}$ & Comments & $\begin{array}{l}\text { Key } \\
\text { entry }\end{array}$ & $\begin{array}{l}\text { Code } \\
\text { shown }\end{array}$ & Comments & Registers: \\
\hline LBL & 23 & & $\mathrm{CHS}$ & 42 & & \\
\hline A & 11. & . & 8 & 08 & & $R_{2}: A_{0}$ \\
\hline $\mathrm{R} / \mathrm{S}$ & 84 & Enter $\rho_{0}\left(\mathrm{~g} / \mathrm{cm}^{3}\right)$ & $\mathrm{RCL} \perp$ & 3401 & & \\
\hline S'n 1 & 3.301 & & $x$ & 71. & & $R_{3}: R_{2}$ (prog. 1$)$ \\
\hline 1 & 01 & & sto 5 & 3305 & & $R-A_{0} T+\Delta R$ \\
\hline$R / S$ & 84 & Enter $\rho_{\mathrm{g}}\left(\mathrm{g} / \mathrm{cm}^{3}\right)$ & LBL & 23 & & \\
\hline STO 5 & 3305 & & c & 13 & & $R_{4}: \gamma$ \\
\hline 2 & 02 & & RCL 7 & 3407 & Displays yield & \\
\hline $\mathrm{R} / \mathrm{S}$ & 84 & Enter $Z$ (wt. fract. $\mathrm{H}_{2} \mathrm{O}$ ) & $\mathrm{R} / \mathrm{S}$ & 84 & Enter tiune ( $\mu s)$ & $R_{5}: \rho_{g}$ \\
\hline STo 6 & 3306 & & STu 7 & 3307 & & 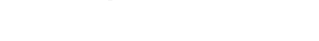 \\
\hline$\cdot$ & 83 & & $\mathrm{RCL} 3$ & 3403 & Enter radius $(\mathrm{cm})$ & $\rho_{0}(1.6010665 \times 10$ \\
\hline 4 & 04 & NOTE: 0.42 is used above $130 \mathrm{~kb}$. & $\mathrm{R} / \mathrm{S}$ & 84 & & . \\
\hline$x$ & $7 . \mathrm{L}$ & $1.5 Z$ should be used for & Sro 3 & 3303 & & $\mathrm{R}_{\gamma}: \mathrm{z}$ \\
\hline 2 & 02 & stress below $130 \mathrm{~kb}$. & $\mathrm{KCL} 7$ & 3407 & 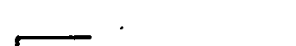 & $(3 \gamma-1) /(\gamma-1)(\gamma+1)$ \\
\hline$\cdot$ & 83 & & KCL 2 & 3402 & $\Gamma$ & \\
\hline 6 & 06 & & $x$ & 71 & $R-\Lambda_{0} T+\Delta R$ & $\mathrm{R}_{7}: \mathrm{T}_{2}$ (prog. 1) \\
\hline RCL ; & 3405 & $\gamma=0.421\left[\left(2.6 \rho_{\mathrm{g}} / \rho_{0}\right)-(12)\right]$ & - & 51. & & \\
\hline$x$ & 71 & & RCL 8 & 3408 & & $\mathrm{R}_{8}: \quad \Delta \mathrm{R}$ \\
\hline RCL 1 & 3401 & $\times\left[(1-z) \rho_{0} / \rho_{g}\right]^{3}+1$ & + & 6.1. & L & \\
\hline$\div$ & 81 & & sto 3 & 3303 & & Labels: \\
\hline 1 & 01 & & $\mathrm{RCL} 4$ & 3404 & r & \\
\hline RCL 6 & 3406 & & 3 & 03 & & A: $\quad \gamma$ calc. \\
\hline - & 51 & & $x$ & 71 & & $C: R, T_{0}$ yleld loop \\
\hline- & 51 & . & 1 & 01 & & \\
\hline 1 & 01 & & - & 51 & & \\
\hline RCL 6 & 3406 & & RCL 4 & 3404 & & \\
\hline- & 51 & & 1 & 01 & $(3 \gamma-1) /(\gamma-1)(\gamma+1)$ & \\
\hline RCL 1 & 3401 & See Ref. 23. & - & 51 & & \\
\hline$\times$ & 71 & & RCL 4 & 3404 & & \\
\hline RCL 5 & 3405 & - & 1 & 01 & & \\
\hline$\div$ & 81 & & + & 61 & & \\
\hline 5 & 05 & & Enter & 41 & & \\
\hline 8 & 35 & $\cdot$ & $x$ & 71 & & \\
\hline$y^{x}$ & 05 & $\cdot$ & $x$ & 71 & & \\
\hline$\times$ & 71 & & $\div$ & 81 & $L$ & \\
\hline 1 & 01 & & STO 6 & 3306 & & \\
\hline+ & 61 & & RCL 3 & 3403 & & \\
\hline+ & 61 & L & 5 & 05 & & \\
\hline STO 4 & 3304 & 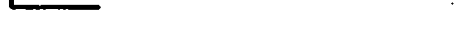 & .8 & 35 & Y1eld $=\left[\rho_{0}(1.6 \times]\right.$ & $\left.\left.{ }^{-8}\right)(3 \gamma-1) /(\gamma-1)(\gamma+1)\right]$ \\
\hline$R / S$ & 84 & D1splay $Y$ & $y^{x}$ & 05 & & \\
\hline 1 & 01 & & $x$ & 71 & $x\left(R-A_{0} T\right.$ & $\Delta \mathrm{R})^{5} / \mathrm{r}^{2}$ \\
\hline - & 83 & & RCL 7 & 3407 & & \\
\hline 6 & 06 & & ENTER & 41 & & \\
\hline 0 & 00 & & $x$ & 71 & & \\
\hline 1 & 01 & & $\div$ & 81 & & \\
\hline 0 & 00 & & RCL 5 & 3405 & & \\
\hline 6 & 06 & & $x$ & 71 & & \\
\hline 6 & 06 & & STO 7 & 3307 & Lield (kt) & \\
\hline 5 & 05 & & GTO & 22 & & \\
\hline EEX & 43 & & $\mathrm{c}$ & 13 & & \\
\hline
\end{tabular}


Table A-3. User instructions for slifer yield programs. Program $1\left(\Delta R, A_{0}\right)$, enter three R, $\mathrm{T}$ points. Program $2\left(\gamma\right.$, yield), enter $\rho_{0}, \rho_{g}, Z$.

\begin{tabular}{|c|c|c|c|c|c|}
\hline Step & Instructions & $\begin{array}{l}\text { Input } \\
\text { data/units }\end{array}$ & \multicolumn{2}{|c|}{ Keys } & $\begin{array}{c}\text { Output } \\
\text { data/units }\end{array}$ \\
\hline 1 & Enter PROGRAM 1, key A & & A & & 0 \\
\hline 2 & Enter RADIUS 1, key R/S & $\mathrm{cm}$ & $\begin{array}{l}\text { Enter } \\
\quad \text { R1 }\end{array}$ & $\mathrm{R} / \mathrm{S}$ & \\
\hline 3 & Enter TIME 1, key R/S & $\mu s$ & $\begin{array}{l}\text { Enter } \\
\quad \mathrm{T} 1\end{array}$ & $\mathrm{R} / \mathrm{S}$ & \\
\hline 4 & Enter RADIUS 2, key R/S & $\mathrm{cm}$ & $\begin{array}{l}\text { Enter } \\
\quad \text { R2 }\end{array}$ & $\mathrm{R} / \mathrm{S}$ & \\
\hline 5 & Enter TIME 2, key R/S & $\mu s$ & $\begin{array}{c}\text { Enter } \\
\text { T2 }\end{array}$ & $\mathrm{R} / \mathrm{S}$ & \\
\hline 6 & Enter RADIUS 3, key R/S & $\mathrm{cm}$ & $\begin{array}{l}\text { Enter } \\
\text { R3 }\end{array}$ & $\mathrm{R} / \mathrm{S}$ & \\
\hline 7 & Enter TIME 3, key R/S & $\mu s$ & $\begin{array}{c}\text { Enter } \\
\text { T3 }\end{array}$ & $\mathrm{R} / \mathrm{S}$ & \\
\hline 8 & Display $\Delta \mathrm{R},(+\Delta \mathrm{R}$ adds to $\mathrm{Rm})$ & & & & $\Delta \mathrm{R} \mathrm{cm}$ \\
\hline 9 & $\mathrm{R} / \mathrm{S}$, Display $\mathrm{A}_{0}$ & & $R / S$ & & $\mathrm{~A}_{0} \mathrm{~cm} / \mu \mathrm{s}$ \\
\hline 10 & $\begin{array}{l}\text { If } \Delta \mathrm{R} \text { is large, you may start } \\
\text { over with three new data } \\
\text { points at step } 1 \text { and repeat. } \\
\text { CAUTION: Large } \Delta \mathrm{R} \text { indicates } \\
\text { other methods should be used. }\end{array}$ & & & . & \\
\hline \multirow[t]{3}{*}{11} & $\begin{array}{l}\text { Enter PROG2, key } A(o l d \Delta R \\
\text { and } A_{0} \text { are saved) }\end{array}$ & & $\mathrm{A}$ & . & \\
\hline & If new $\Delta R$, enter $\Delta R$, STO 8 & $\mathrm{~cm}$ & $\begin{array}{c}\text { Enter } \\
\cdot \Delta R\end{array}$ & STO 8 & \\
\hline & If new $A_{0}$, enter $A_{0}$, STO 2 & $\mathrm{~cm} / \mu \mathrm{s}$ & $\begin{array}{c}\text { Enter } \\
\mathrm{A}_{0}\end{array}$ & STO 2 & \\
\hline 12 & Ențer $\rho_{0}$, key $R / S$ & $\mathrm{~g} / \mathrm{cm}^{3}$ & $\begin{array}{c}\text { Enter } \\
\rho\end{array}$ & $\mathrm{R} / \mathrm{S}$ & \\
\hline 13 & Enter $\rho_{g}$, key R/S & $\mathrm{g} / \mathrm{cm}^{3}$ & $\begin{array}{c}\text { Enter } \\
\rho_{\mathrm{g}}\end{array}$ & $\mathrm{R} / \mathrm{S}$ & \\
\hline 14 & $\begin{array}{l}\left.\text { Enter } \mathrm{Z} \text { (wt. frac. } \mathrm{H}_{2} \mathrm{O}\right) \text {, } \\
\text { key R/S }\end{array}$ & : & $\begin{array}{c}\text { Enter } \\
\quad \mathrm{Z}\end{array}$ & $\mathrm{R} / \mathrm{S}$ & \\
\hline 1.5 & $\begin{array}{l}\text { Displays } \gamma \text { (if new } \gamma \text {, key A), } \\
\text { key R/S }\end{array}$ & & & $\mathrm{R} / \mathrm{S}$ & $\gamma$ \\
\hline
\end{tabular}


Table A-3. (Continued).

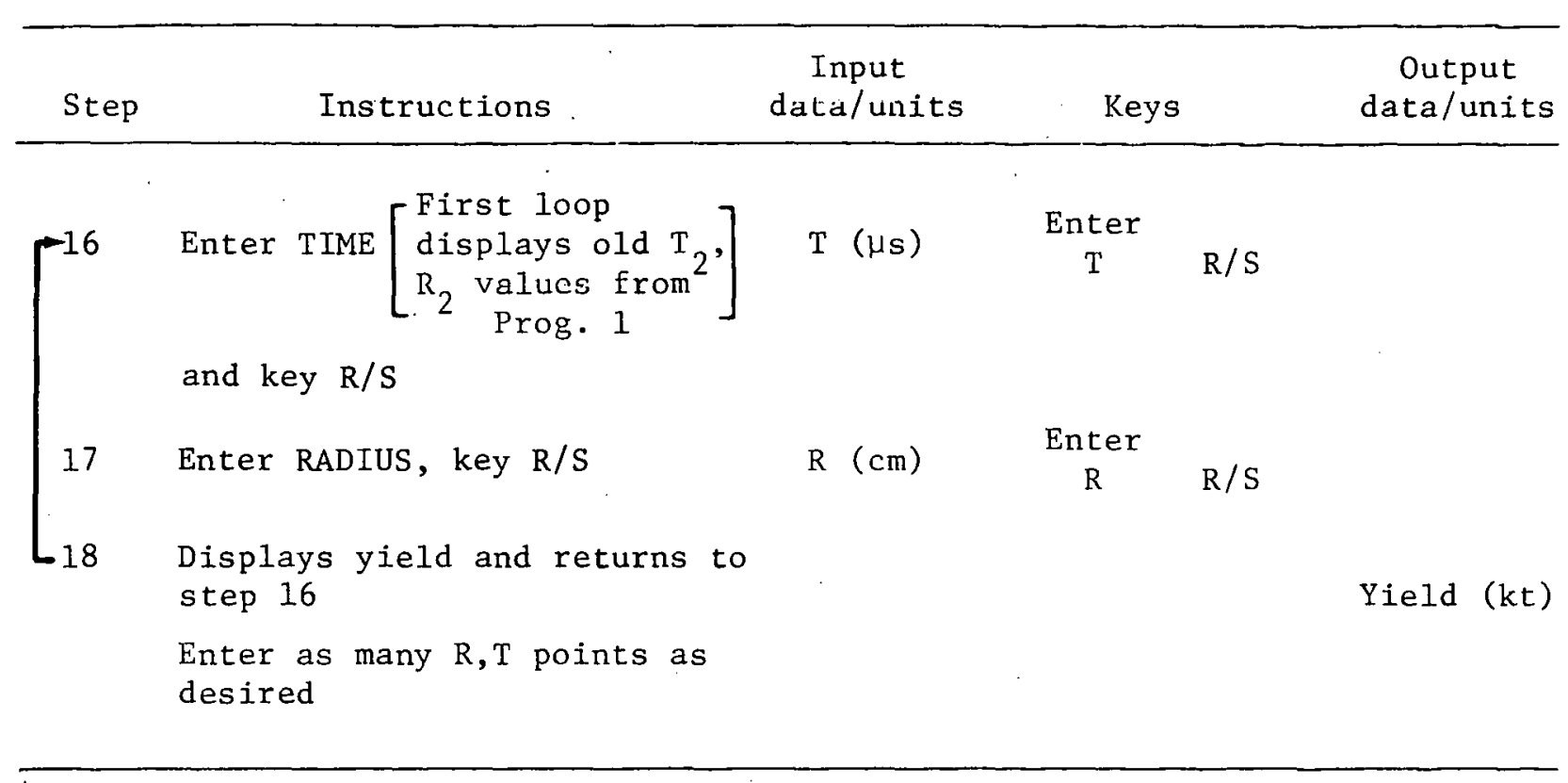




\section{APPENDIX B}

\section{DERIVATION OF $\mathrm{A}_{0}$ AND $\triangle \mathrm{R}$}

A method is suggested for measuring the intercept of the $\mathrm{U}_{\mathrm{s}}-\mathrm{U}_{\mathrm{p}}$ line $\left(A_{0}\right)$ from Eq. 1, $R_{m}=\Xi T^{2 / 5}+A_{0} T$. If an erroneous working point were used in this equation, the derivation of $A_{0}$ would result in an error. The following derivation gives a value for the working point $\Delta R$ as well as an independent measure of $\mathrm{A}_{0}$. From $\mathrm{Eq}$. 1, then:

$$
\frac{\mathrm{R}_{\mathrm{m}}-\mathrm{A}_{0} \mathrm{~T}}{\mathrm{~T}^{2 / 5}}=\Xi
$$

Taking two data points $\left(\mathrm{R}_{\mathrm{m} 1}, \mathrm{~T}_{1} ; \mathrm{R}_{\mathrm{m} 2}, \mathrm{~T}_{2}\right)$, it should then be possible to derive $A_{0}$ provided that the working point is valid.

$$
\frac{\mathrm{R}_{1}-\mathrm{A}_{0} \mathrm{~T}_{1}}{\mathrm{~T}_{1}{ }^{2 / 5}}=\Xi_{1} \quad \frac{\mathrm{R}_{2}-\mathrm{A}_{0} \mathrm{~T}_{2}}{\mathrm{~T}_{2}{ }^{2 / 5}}=\Xi_{2}
$$

Assuming that energy $E$ and Grüneisen $\gamma$ are constant for the data points being considered,

$$
\begin{aligned}
& \Xi_{1}=\Xi_{2} \\
& \left(\mathrm{R}_{1}-\mathrm{A}_{0} \mathrm{~T}_{1}\right) / \mathrm{T}_{1}{ }^{2 / 5}=\left(\mathrm{R}_{2}-\mathrm{A}_{0} \mathrm{~T}_{2}\right) / \mathrm{T}_{2} \\
& \left(\mathrm{~T}_{2} / \mathrm{T}_{1}\right)^{2 / 5} \mathrm{R}_{1}-\left(\mathrm{T}_{2} / \mathrm{T}_{1}\right)^{2 / 5} \mathrm{~T}_{1} \mathrm{~A}_{0}=\mathrm{R}_{2}-\mathrm{A}_{0} \mathrm{~T}_{2} \\
& \mathrm{~A}_{0}\left[\left(\mathrm{~T}_{1} \mathrm{~T}_{2}^{2 / 5} / \mathrm{T}_{1}{ }^{2 / 5}\right)-\mathrm{T}_{2}\right]=\left(\mathrm{T}_{2}{ }^{2 / 5} / \mathrm{T}_{1}{ }^{2 / 5}\right) \mathrm{R}_{1}-\mathrm{R}_{2} \\
& \mathrm{~A}_{0}=\left[\left(\mathrm{T}_{2} / \mathrm{T}_{1}\right)^{2 / 5} \mathrm{R}_{1}-\mathrm{R}_{2}\right] /\left[\left(\mathrm{T}_{2} / \mathrm{T}_{1}\right)^{2 / 5} \mathrm{~T}_{1}-\mathrm{T}_{2}\right]
\end{aligned}
$$

If the working point error is introduced as $R+\Delta R$, which is typical of a vertical displacement problem seen in slifer data, then Eq. B1 becomes the working-point corrected equation by substituting $R_{1}+\Delta R$ for $R_{1}$, and $R_{2}+\Delta R$ for $\mathrm{R}_{2}$. The working-point corrected intercept is $A_{w p}$.

$$
A_{w p}=\left[\left(T_{2} / T_{1}\right)^{2 / 5}\left(R_{1}+\Delta R\right)-\left(R_{2}+\Delta R\right)\right] /\left[\left(T_{2} / T_{1}\right)^{2 / 5} \cdot T_{1}-T_{2}\right]
$$




$$
\begin{aligned}
& =\left[\left(\mathrm{T}_{2} / \mathrm{T}_{1}\right)^{2 / 5} \mathrm{R}_{1}-\mathrm{R}_{2}\right] /\left[\left(\mathrm{T}_{2} / \mathrm{T}_{1}\right)^{2 / 5} \mathrm{~T}_{1}-\mathrm{T}_{2}\right] \\
& +\left[\left(\mathrm{T}_{2} / \mathrm{T}_{1}\right)^{2 / 5}-1\right] \Delta \mathrm{R} /\left[\left(\mathrm{T}_{2} / \mathrm{T}_{1}\right)^{2 / 5} \mathrm{~T}_{1}-\mathrm{T}_{2}\right]
\end{aligned}
$$

Noting that the first term is Eq. B1, $A_{0}$ is now substituted into Eq. B2 with subscripts pertaining to the data points used:

$$
\begin{aligned}
A_{w p} & =A_{1,2}+\left[\left(\mathrm{T}_{2} / \mathrm{T}_{1}\right)^{2 / 5}-1\right] \Delta \mathrm{R} /\left[\left(\mathrm{T}_{2} / \mathrm{T}_{1}\right)^{2 / 5} \mathrm{~T}_{1}-\mathrm{T}_{2}\right] \\
& \left.=\mathrm{A}_{3,4}+\left[\left(\mathrm{T}_{4} / \mathrm{T}_{3}\right)^{2 / 5}-1\right] \Delta \mathrm{R} /\left[\mathrm{T}_{4} / \mathrm{T}_{3}\right)^{2 / 5} \mathrm{~T}_{3}-\mathrm{T}_{4}\right]
\end{aligned}
$$

where

$$
A_{1,2}=\left[\left(T_{2} / T_{1}\right)^{2 / 5} R_{1}-R_{2}\right] /\left[\left(T_{2} / T_{1}\right)^{2 / 5} T_{1}-T_{2}\right]
$$

and

$$
\mathrm{A}_{3,4}=\left[\left(\mathrm{I}_{4} / \mathrm{I}_{3}\right)^{2 / 5} \mathrm{R}_{3}-\mathrm{R}_{4}\right] /\left[\left(\mathrm{T}_{4} / \mathrm{T}_{3}\right)^{2 / 5} \mathrm{~T}_{3}-\mathrm{T}_{4}\right]
$$

Solving for $\Delta \mathrm{R}$ results in

$$
\begin{aligned}
\Delta R & =\left(A_{3,4}-A_{1,2}\right) /\left\{\left[\left(T_{2} / T_{1}\right)^{2 / 5}-1\right] /\left[\left(T_{2} / T_{1}\right)^{2 / 5} T_{1}-T_{2}\right]\right. \\
& \left.-\left[\left(T_{4} / T_{3}\right)^{2 / 5}-1\right] /\left[\left(\mathrm{T}_{4} / T_{3}\right)^{2 / 5} T_{3}-T_{4}\right]\right\}
\end{aligned}
$$

Substituting for the denominator terms,

$$
\begin{aligned}
W_{1,2} & =\left[\left(\mathrm{T}_{2} / \mathrm{T}_{1}\right)^{2 / 5}-1\right] /\left[\left(\mathrm{T}_{2} / \mathrm{T}_{1}\right)^{2 / 5} \mathrm{~T}_{3}-\mathrm{T}_{2}\right] \\
\mathrm{W}_{3,4} & =\left[\left(\mathrm{T}_{4} / \mathrm{T}_{3}\right)^{2 / 5}-1\right] /\left[\left(\mathrm{T}_{4} / \mathrm{T}_{3}\right)^{2 / 5} \mathrm{~T}_{3}-\mathrm{T}_{4}\right] \\
\Delta \mathrm{R} & =\left(\mathrm{A}_{3,4}-\mathrm{A}_{1,2}\right) /\left(\mathrm{W}_{1,2}-\mathrm{W}_{3,4}\right)
\end{aligned}
$$

Using three data points results in

$$
\Delta R=\left(A_{2,3}-A_{1,2}\right) /\left(W_{1,2}-W_{2,3}\right)
$$




\title{
DO NOT MICROFILM COVER
}

\author{
NOTICE
}

This report was prepared as an account of work sponsored by the United States Government. Neither the United States nor the United States Energy Research \& Development Administration, nor any of their employees, nor any of their contractors, subcontractors, or their employees, makes any warranty, express or implied, or assumes any legal liability or responsibility for the accuracy, completeness or usefulness of any information, apparatus, product or process disclosed, or represents that its use would not infringe privately-owned rights.

\section{NOTICE}

Reference to a company or product name does not imply approval or recommendation of the product by the University of California or the U.S. Energy Research \& Development Administration to the exclusion of others that may be suitable.

Printed in the United States of America Available from

National Technical Information Service

U.S. Department of Commerce

5285 Port Royal Road

Springfield, VA 22161

Price: Printed Copy $\$$

Microfiche $\$ 3.00$

\begin{tabular}{|c|c|c|c|}
\hline Page Range & $\begin{array}{c}\text { Domestic } \\
\text { Price } \\
\end{array}$ & Page Range & $\begin{array}{c}\text { Domestic } \\
\text { Price }\end{array}$ \\
\hline $001-025$ & $\$ 3.50$ & $326-350$ & 10.00 \\
\hline $026-050$ & 4.00 & $351-375$ & 10.50 \\
\hline $051-075$ & 4.50 & $376-400$ & 10.75 \\
\hline $076-100$ & 5.00 & $401-425$ & 11.00 \\
\hline $101-125$ & 5.50 & $426-450$ & 11.75 \\
\hline $126-150$ & 6.00 & $451-475$ & 12.00 \\
\hline $151-175$ & 6.75 & $476-500$ & 12.50 \\
\hline $176-200$ & 7.50 & $501-525$ & 12.75 \\
\hline $201-225$ & 7.75 & $526-550$ & 13.00 \\
\hline $226-250$ & 8.00 & $551-575$ & 13.50 \\
\hline $251-275$ & 9.00 & $576-600$ & 13.75 \\
\hline $276-300$ & 9.25 & $601-u p$ & $*$ \\
\hline $301-325$ & 9.75 & & \\
\hline
\end{tabular}

*Add $\$ 2.50$ for each additional 100 page increment from 601 to 1.000 pages: add $\$ 4.50$ for each additional 100 page increment over 1,000 pages. 
Technical Information Department

LAWRENCE LIVERMORE LABORATORY

University of California | Livermore, California | 94550

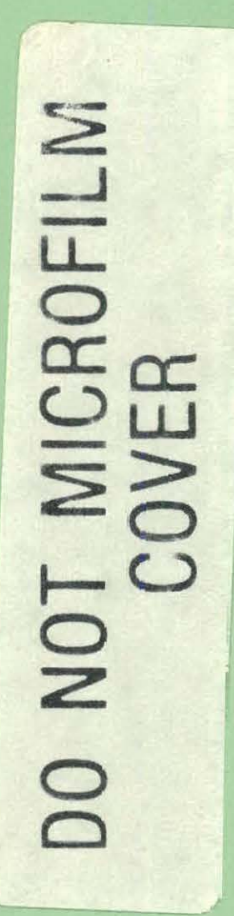

